\title{
Degradation Analysis of NBR and Epichlorohydrin Rubber by New Micro Analysis Method
}

\author{
Hisao KATOH $^{1, *}$, Ritsu Kamoto ${ }^{2}$ and Jun Murata ${ }^{1}$ \\ ${ }^{1}$ Canon Inc., 4202 Fukara, Susono-shi, Shizuoka 410-1196, Japan \\ ${ }^{2}$ Micro Analysis Lab Inc., 382-27 Obayashi, Moriyama-shi, Shiga 524-0054, Japan \\ *Corresponding author: kato.hisao@canon.co.jp \\ Received December 14, 2005; Revised January 27, 2006; 2nd Revised February 20, 2006; Accepted March 7, 2006 \\ (C) 2006 The Society of Rubber Industry, Japan
}

\begin{abstract}
The degradation analysis of NBR and Epichlorohydrin rubber was carried out by infrared micro spectroscopy $(\mu$-IR) and micro sampling mass spectrometry ( $\mu$-MS) which gives information on the scission and crosslinking of rubber molecules. Samples were prepared by three different treatments, heat as well as ultra violet (UV) and electron beam (EB) irradiations.

It was found for NBR vulcanizates that the heat treatment induced the oxidation, scission and crosslinking of rubber molecules. By the UV treatment, chain scission and crosslinking accompanied by a slight oxidation were induced. The EB treatment enhanced the crosslinking, however, the extent of oxidation was negligible. For Epichlorohydrin rubber vulcanizates, the heat treatment accelerated chain scission rather than crosslinking. On the other hand, the oxidation and crosslinking were induced by the UV and EB treatments.
\end{abstract}

Keywords Degradation, NBR, Epichlorohydrin rubber, $\mu$-MS, $\mu$-IR, Oxidation, Crosslinking, Chain scission.

\section{Introduction}

NBR and Epichlorohydrin rubber are used widely in the conductive rollers such as charging roller, developing roller and transfer roller for electrophotographic apparatus (Figure 1).

The surface of these rollers loses rubber elasticity when they are used under severe conditions such as discharging, high temperature and high humidity. Thus, the surface characterization of the roller is very important.

The degradation of NBR and Epichlorohydrin rubber has been investigated by many researchers using various techniques. For NBR, it is known that hydroxyl, carbonyl, and ester groups were formed by heat, resulting in the increase of modulus ${ }^{1}$. The degradation of Epichlorohydrin rubber by heat was found to proceed by two steps. The first is an oxidation and the second is a de-hydrochloric acid, resulting in the softening of rubber $^{2}$. Infrared micro spectroscopy gives information on the formation of carbonyl, carboxylic acid and ester produced by the oxidation $^{1,3,4)}$. However, it is difficult to obtain information on the changes in the molecular structure such as a chain scission and crosslinking of rubber molecules. Micro sampling mass spectrometry ( $\mu$-MS) is a newly developed microanalysis method. It gives information on the chain scission and the change of crosslinking density in the vulcanizates as the peak shift of Total Ion Chromatogram (TIC) $)^{5,6)}$.

In this study, NBR and Epichlorohydrin rubber vulcanizates were treated by three different methods such as heat as well as ultra-violet (UV) and electron beam (EB) irradiations. The samples were analyzed by $\mu$-IR and $\mu$ MS.

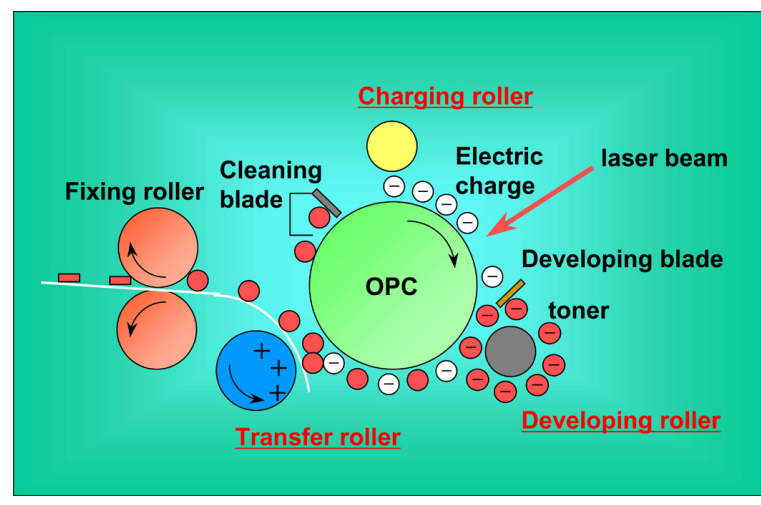

Figure 1. Schematic drawing of electrophotographic apparatus. 


\section{Experimental}

\section{Materials}

The formulations used for NBR and Epichlorohydrin rubber compounds are as follows.

NBR compound (phr): NBR 100, zinc oxide 5, stearic acid 1, 2-Mercaptobenzothiazole 1, Dibenzothiazyl disulfide 2, sulfur 1.2 (NBR: DN201; Zeon Co.)

Epichlorohydrin rubber compound (phr): Epichlorohydrin rubber 100, zinc oxide 5, stearic acid 1, Tetramethylthiuram monosulfide 1, Dibenzothiazyl disulfide 1, sulfur 1.2 (Epichlorohydrin rubber: CG102; Daiso Co.)

Curing: $160^{\circ} \mathrm{C} \times 30 \mathrm{~min}$ in press followed by $160^{\circ} \mathrm{C} \times 2$ hrs in oven.

The thickness of the vulcanized rubber sheet was $2 \mathrm{~mm}$.

The sample size used for the aging treatments was $3 \mathrm{~mm}$ $(\mathrm{W}) \times 3 \mathrm{~mm}(\mathrm{~L}) \times 2 \mathrm{~mm}(\mathrm{~T})$.

\section{Aging treatments}

Heat treatments were carried out in an air oven at $180^{\circ} \mathrm{C}$ for 4 and $8 \mathrm{hrs}$.

UV treatments $\left(254 \mathrm{~nm}, 0.5 \mathrm{~kW}, 27000 \mathrm{~mJ} / \mathrm{cm}^{2}\right.$ (30 min) and $54000 \mathrm{~mJ} / \mathrm{cm}^{2}(60 \mathrm{~min})$ ) were made in the air at an ambient temperature with the use of UV lamp.

EB treatments $(150 \mathrm{kv}, 1000 \mathrm{kGy}$ and $3000 \mathrm{kGy})$ were made in $\mathrm{N}_{2}$ gas (oxygen concentration $300 \mathrm{ppm}$ ) with the use of electron beam irradiation apparatus (CB150; Iwasaki Electric Co.).

\section{Measurements}

The samples for the measurements were prepared by cutting off the surface of rubber sheet under an optical microscope. The size was approximately $20 \mu \mathrm{m} \phi$ in diameter and $20 \mu \mathrm{m}$ in thickness.

The infrared micro spectrometer (AIM8000R; Shimadzu Co.) with highly sensitive liquid nitrogen cooled MCTdetector was used. The specimen was set on $\mathrm{ZnSe}$ crystal and spectra were recorded by transmission mode at room temperature.

$\mu$-MS measurements were performed by the use of mass device installed in Polaris Q (Thermo Electron Co.). The outline of $\mu$-MS measurement is shown in Figure 2. The specimen was set on a filament at the tip of probe and inserted in an ionization chamber of the mass device. The specimen was rapidly heated up to $1000^{\circ} \mathrm{C}$ under a constant heating rate, vaporized and ionized by the irradiation of the electron beam. Ionized mass fragment produced was detected by mass spectrometer. As the heating rate was constant, thermo chromatograms called

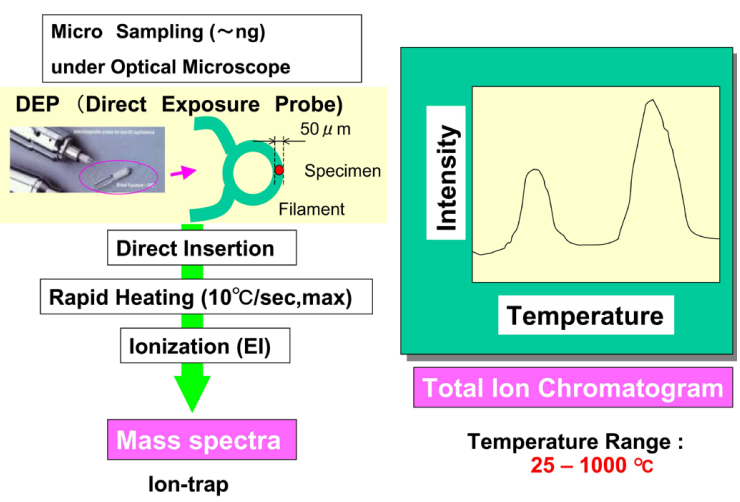

Figure 2. Outline of micro sampling mass spectrometry.

total ion chromatogram (TIC) were obtained, similar to the TG-MS with the mass spectra.

$\mu$-MS has three characteristics. First, the sample size for the measurement is extremely small (order of nanogram). Second, as the temperature can be raised up to more than $1000^{\circ} \mathrm{C}$ at a constant rate, the pre-treatment is not necessary for the polymeric materials. Third, it is possible to get mass spectra in the form of individual peak for the mixtures with different vaporization temperature (e.g. low molecular weight compound, high molecular weight compound). As the gasified temperature is accurate, it is possible to use the total ion chromatogram (TIC) as a thermo chromatogram. For the direct insert (DI) method, the temperature can be raised at a constant rate, however, accuracy of actual temperature is not reliable and the maximum temperature is limited to $350^{\circ} \mathrm{C}$ (relatively low temperature). Therefore, the DI method is not suitable for the analysis of polymeric materials directly.

\section{Results and Discussion}

\section{Total Ion Chromatograms}

Total ion chromatograms of NBR (raw), unvulcanized NBR (compound) and vulcanized NBR are shown in Figure 3. NBR (raw) showed a single peak at $417^{\circ} \mathrm{C}$. On the other hand, unvulcanized NBR showed a double peak, 403 and $417^{\circ} \mathrm{C}$, respectively. The peak temperature at the lower temperature side indicates that a chain scission occurred during mixing process. Because, the mixing was carried out under a high shear stress, resulting in the increase of temperature. In fact, it is confirmed by GPC measurements that molecular weight decreased from 444000 (NBR raw) to 374000 (unvulcanized NBR). For the vulcanized NBR, the peak temperature was $45^{\circ} \mathrm{C}$ higher than that for unvulcanized one. The difference might be due to the increase of crosslink density of NBR 


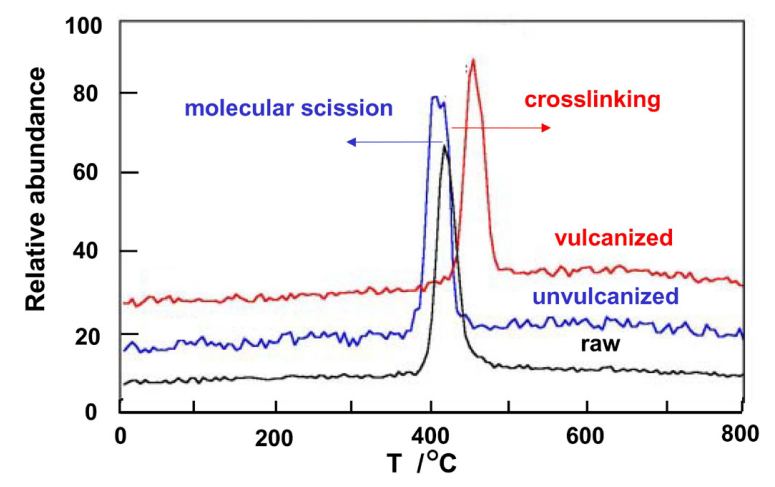

Figure 3. Total ion chromatograms of NBR (raw), unvulcanized and vulcanized NBR.
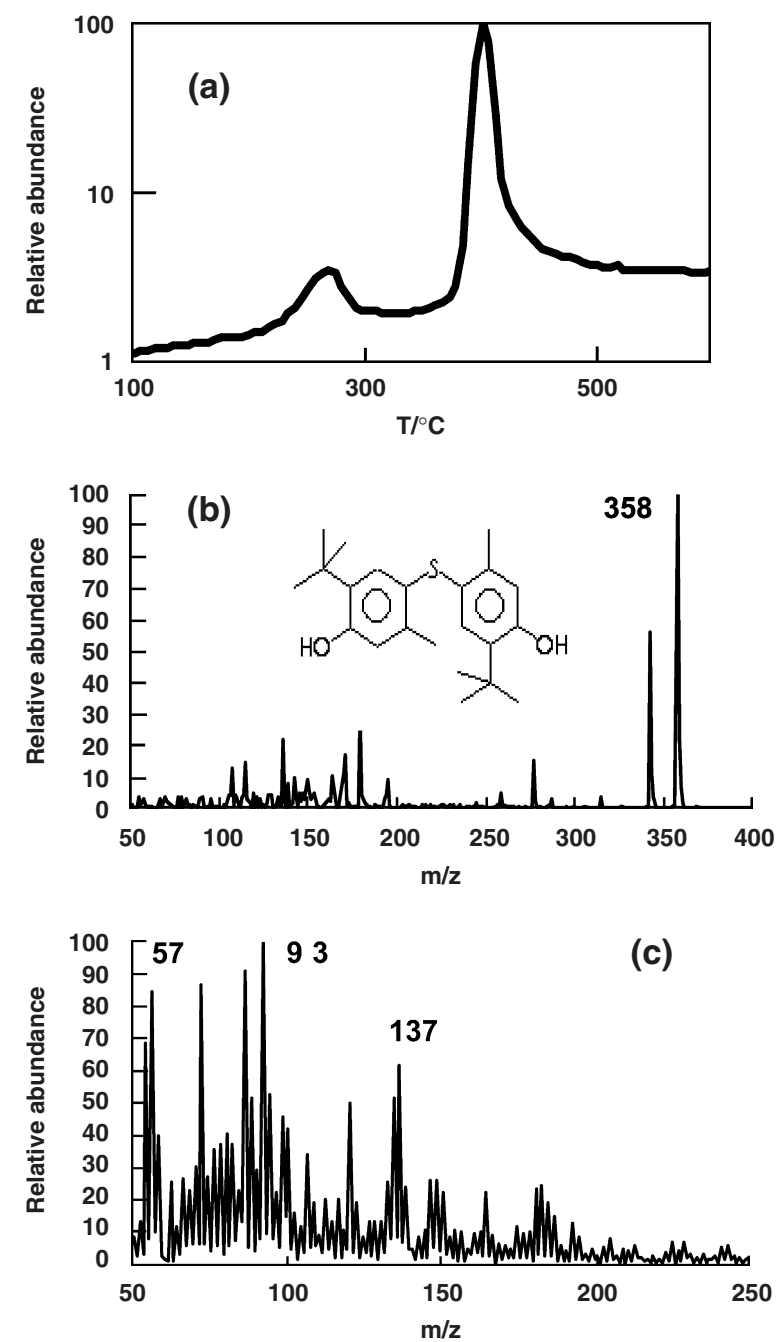

Figure 4. (a) Total ion chromatogram of Epichlorohydrin rubber. (b) Mass spectrum of TIC peak top at $270^{\circ} \mathrm{C}$. (c) Mass spectrum of TIC peak top at $403^{\circ} \mathrm{C}$.

molecules $^{6,7)}$.

Total ion chromatogram of Epichlorohydrin rubber

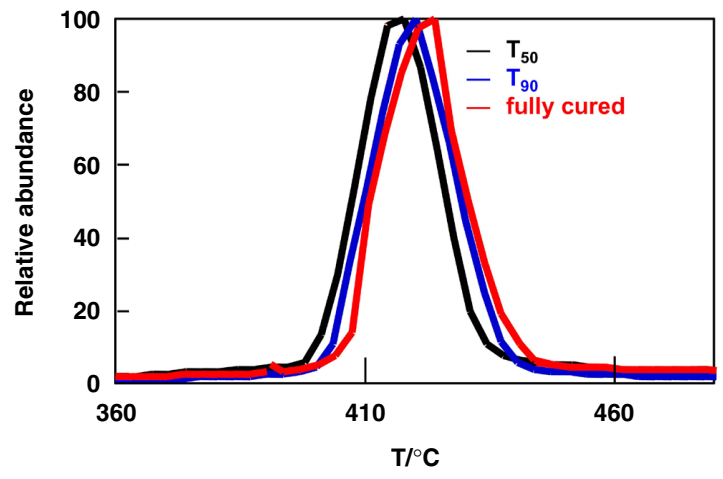

Figure 5. Total ion chromatograms of $\mathrm{T}_{50}, \mathrm{~T}_{90}$ and fully cured Epichlorohydrin rubber vulcanizates.

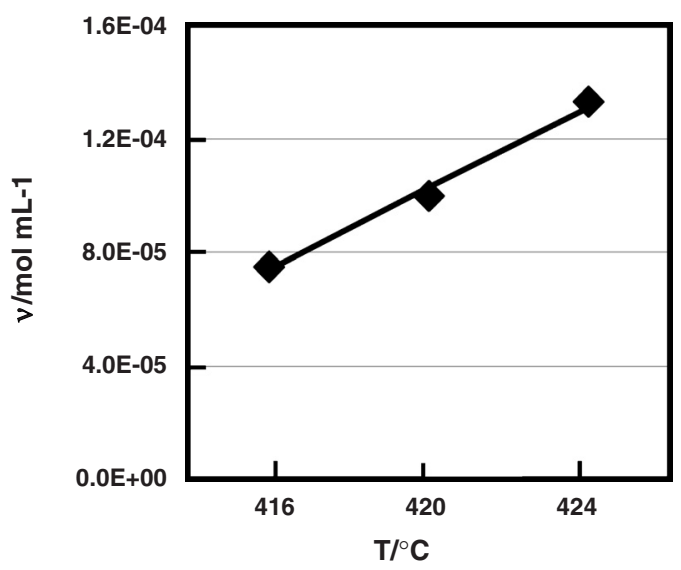

Figure 6. Relation between crosslink density and peak temperature of TIC for $\mathrm{T}_{50}, \mathrm{~T}_{90}$ and fully cured Epichlorohydrin rubber vulcanizates.

(raw) is shown in Figure 4(a). Two peaks were observed at 270 and $403^{\circ} \mathrm{C}$. The small peak at $270^{\circ} \mathrm{C}$ and a large peak at $403^{\circ} \mathrm{C}$, might be responsible for the antioxidant $\left(4,4^{\prime}\right.$ thiobis (6-tert-butyl-3-methylphenol)) and Epichlorohydrin rubber, respectively, judging from the mass spectra at 270 and $403^{\circ} \mathrm{C}$, shown in Figures 4(b) and 4(c), respectively. If so, the $\mu$-MS can analyze additives and polymer individually as the differences of gasification temperature.

Total ion chromatograms of $\mathrm{T}_{50}, \mathrm{~T}_{90}$ and fully cured $\left(160^{\circ} \mathrm{C} \times 30 \mathrm{~min}+160^{\circ} \mathrm{C} \times 2 \mathrm{hrs}\right) \quad$ Epichlorohydrin rubber vulcanizates are shown in Figure 5. The peaks for the $\mathrm{T}_{50}$, $\mathrm{T}_{90}$ and fully cured samples were observed at 416,420 and $424^{\circ} \mathrm{C}$, respectively. That is, the peak temperature shifted to higher temperature side as the cure time increased. The crosslink densities of $\mathrm{T}_{50}, \mathrm{~T}_{90}$ and fully cured samples were obtained by Flory-Rehner equation ${ }^{8)}$, and the results are plotted as a function of peak temperature of TIC in Figure 6. A linear relation can be seen in the figure. This means 
that the crosslink density in the rubber compound reflects the peak temperature in the TIC.

\section{Degradation analysis}

\section{NBR vulcanizates}

$\mu$-IR spectra and the TICs of $\mu$-MS for the samples which were treated by heat, UV and EB are shown in Figures 7 and 8, respectively. By the heat treatment, carbonyl, carboxylic acid $\left(1650 \sim 1730 \mathrm{~cm}^{-1}\right)$ and ester $\left(1200 \mathrm{~cm}^{-1}\right)$ absorption intensities increased drastically, in accordance with the previous report ${ }^{1,4)}$. However, such changes were minor in the samples treated by the UV and negligible for the EB treatments. This means that the extent of changes in the chemical structure of NBR by the oxidation is the order of heat $>\mathrm{UV}>\mathrm{EB}$.

The peak of TIC shifted to higher temperature side and a shoulder appeared on the lower temperature side of the peak by the heat treatment. For the UV treated samples,

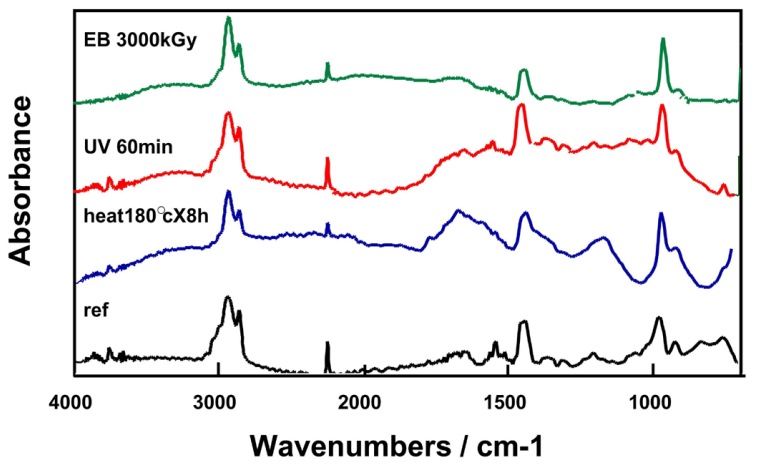

Figure 7. $\mu$-IR spectra for untreated (ref) and heat $\left(180^{\circ} \mathrm{C} \times 8 \mathrm{hrs}\right)$, UV (60 min), EB (3000 kGy) treated NBR vulcanizates.

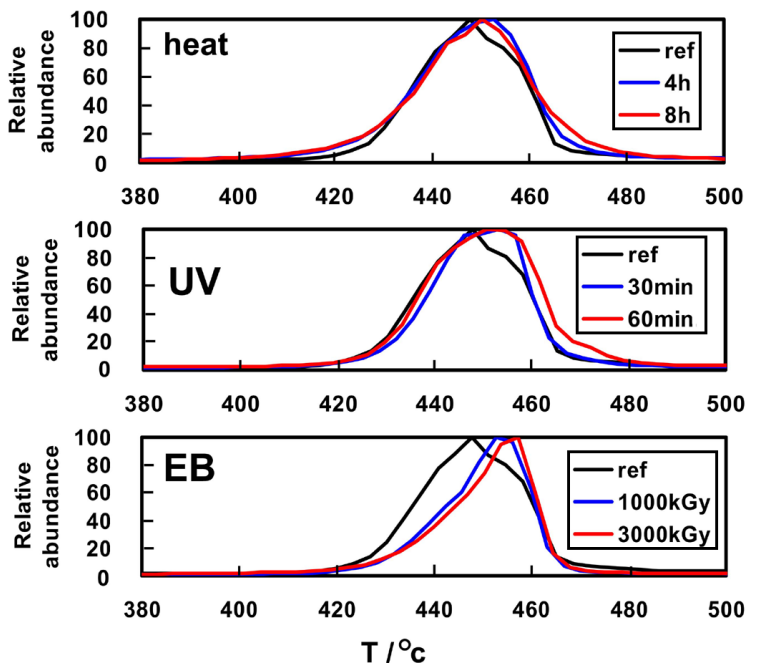

Figure 8. TICs for untreated (ref) and heat $\left(180^{\circ} \mathrm{C} \times 4,8 \mathrm{hrs}\right)$, UV $(30,60 \mathrm{~min}), \mathrm{EB}(1000,3000 \mathrm{kGy})$ treated NBR vulcanizates. the peak shifted to higher temperature side with the increase of the irradiation time. This was accompanied by the appearance of shoulder on the lower temperature side of the peak. By the EB treatment, the peak also shifted to higher temperature side. However, the development of shoulder at lower temperature side of the peak observed in the heat and UV treated samples was negligible. These results reveal that the heat treatment accelerates chemical oxidation, chain scission and an increase of crosslink density of NBR molecules. Although the increase of crosslink density was observed in both UV and EB treated samples, the oxidation and scission of NBR were less prominent compared with those for heat treated samples.

\section{Epichlorohydrin vulcanizates}

$\mu$-IR spectra and TICs for the samples, which were treated by heat, UV and EB, are shown in Figures 9 and 10. It is seen in Figure 9 that the absorption peak intensity $\left(1650 \sim 1730 \mathrm{~cm}^{-1}\right)$ responsible for the carbonyl, carboxylic acid groups was dependent on the sort of aging treatment. The extent was the order of $\mathrm{UV}>\mathrm{EB}>$ heat. The results were different from those for NBR. This means that the extent of oxidation depends on the chemical structure of rubber as well as the sort of aging treatment.

As seen in Figure 10, TIC peak temperature shifted to lower temperature side by the heat treatment. However, the peak shifted to higher temperature side by both UV and EB treatments with this tendency more prominent in the samples treated by the EB. These results suggest that the heat treatment accelerates the chain scissions rather than the crosslinking by the chlorine radicals. On the other hand, both UV and EB treatments enhance the crosslinking by the oxidation.

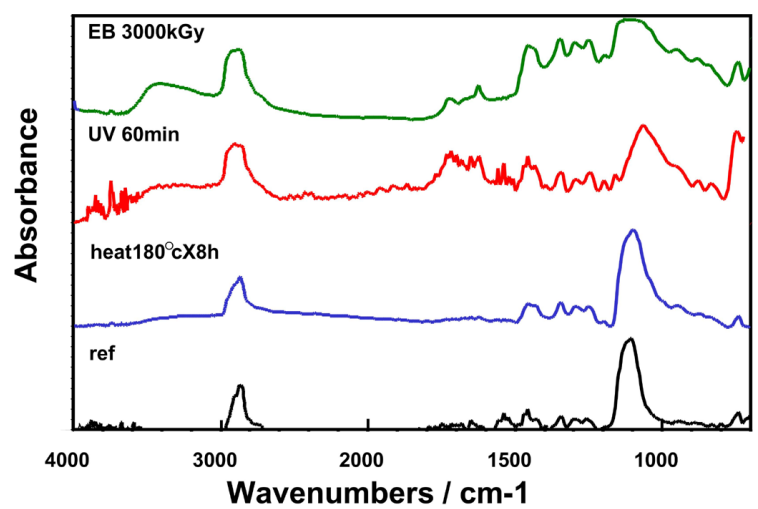

Figure 9. $\mu$-IR spectra for untreated (ref) and heat $\left(180^{\circ} \mathrm{C} \times 8 \mathrm{hrs}\right)$, UV $(60 \mathrm{~min})$, EB $(3000 \mathrm{kGy})$ treated Epichlorohydrin rubber vulcanizates. 

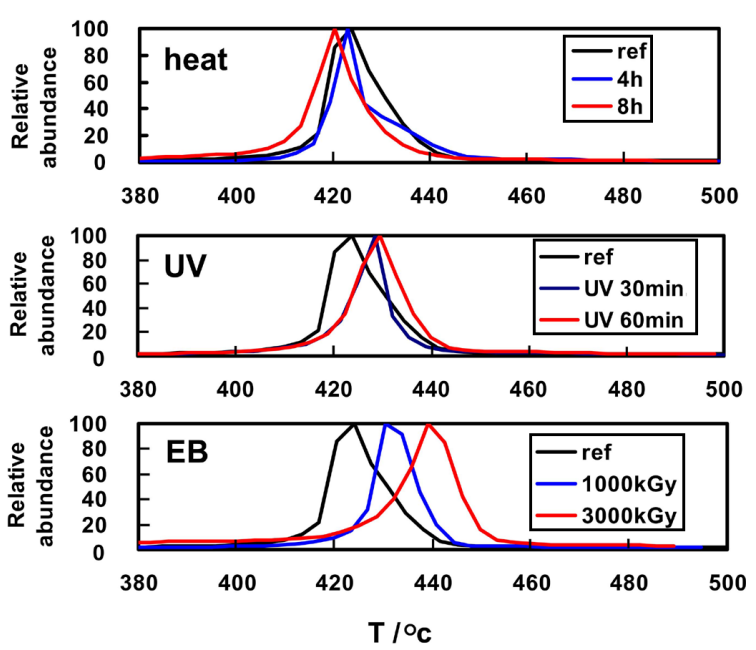

Figure 10. TICs for untreated (ref) and heat $\left(180^{\circ} \mathrm{C} \times 4,8 \mathrm{hrs}\right)$, UV (30, $60 \mathrm{~min})$, EB $(1000,3000 \mathrm{kGy})$ treated Epichlorohydrin rubber vulcanizates.

\section{Conclusions}

The degradation analysis of NBR and Epichlorohydrin rubber vulcanizates was carried out by using infrared micro spectroscopy ( $\mu$-IR) and micro sampling mass spectrometry ( $\mu$-MS), a new microanalysis method. Samples were prepared by three different aging treatments (heat, UV and EB). For NBR, oxidation, chain scission and crosslinking occurred by the heat treatments. By the
UV treatments, chain scission and crosslinking accompanied by a slight oxidation were induced. The EB treatments enhanced the crosslinking, however, the extent of chain scission was negligible.

For Epichlorohydrin rubber, the heat treatments accelerated chain scission rather than crosslinking. On the other hand, both UV and EB treatments enhanced the crosslinking by the oxidation without breaking down of rubber molecules.

These results indicate that the degradation of rubber vulcanizates depends on the chemical structure of rubber molecules as well as the sort of aging treatment.

\section{References}

1) Celina M., Wise J., Ottesen K. D., Gillen T. K., Clough L. R.: Polym. Degrad. Stabil., 60, 493 (1998).

2) Yamada M., Arai S., Masuda Y.: Nippon Gomи Kyoukaisi, 46, 404 (1973).

3) Kuramasu H.: Nippon Gomи Kyoukaisi, 67, 798 (1994).

4) Kawashima T., Ogawa T.: Nippon Goти Kyoukaisi, 75, 257 (2002).

5) Kamoto R., Ishida H., Katagiri G.: JSAC $42^{\text {nd }}$ Annual Meeting at Hiroshima (1993).

6) Kamoto R., Takano K.: SRIJ $14^{\text {th }}$ Elastomer Symposium at Osaka (2001).

7) Katoh H., Murata J., Nishimura Y., Kamoto R.: SRIJ Annual Meeting at Osaka (2003).

8) Flory J. P., Rehner J.: J. Chem. Phys., 11, 521 (1943). 